\title{
Ergonomia em edificações adaptadas: análise ergonômica da adaptação de uma residência unifamiliar em um restaurante popular.
}

\author{
Ergonomics in adapted buildings: ergonomic analysis of a single family \\ residence adaptation into a casual restaurant.
}

\author{
PINTO, Anne Karolinne Tavares \\ Universidade Federal de Pernambuco, Bacharel \\ annekarolinne@outlook.com
}

\author{
OLIVEIRA BISNETA, Adalgiza Cabral de \\ Universidade Federal de Pernambuco, Graduanda \\ adalgizacabral@outlook.com
}

\section{FLORÊNCIO, André Vinícius Barbosa}

Universidade Federal de Pernambuco, Graduando

andvinib@gmail.com

\author{
BARROS, Bruno Xavier da Silva \\ Universidade Federal de Pernambuco, MSc. \\ barros_bruno@hotmail.com
}

\begin{abstract}
RESUMO
O sistema educacional brasileiro tem levado o ensino superior a localidades cada vez mais distantes das capitais. As universidades têm sido uma realidade agora acessível em cidades urbanisticamente menos desenvolvidas do interior do país. Nem sempre os locais de instalação dos centros de ensino são providos de estabelecimentos comerciais em seu entorno, comprometendo a permanência de alunos e professores por longos períodos de tempo no campus. Neste sentido, a presente pesquisa apresenta uma análise ergonômica da adaptação de parte de uma residência unifamiliar no único restaurante popular das proximidades de um campus universitário relativamente recente em uma cidade do interior do nordeste. A metodologia utilizada consistiu na aplicação de etapas da Metodologia para Projetos de Construção Centrados no Ser Humano. A pesquisa possibilitou a identificação de diversos pontos de inadequação, os quais comprometem a qualidade da atividade, bem como a segurança dos usuários no espaço. A partir dos resultados da análise foi apresentada uma lista de recomendações ergonômicas e uma proposta de um novo leiaute que atendesse a todas as alterações sugeridas.
\end{abstract}

Análise ergonômica, Restaurante, Ergonomia do ambiente construído, Edificações adaptadas. 


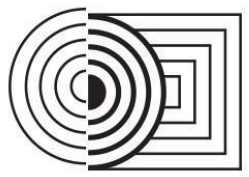

\title{
$17^{\circ}$ ERGODESIGN \& USIHC 2019 \\ PUC-Rio, 11 a 13 de dezembro \\ Rio de Janeiro, RJ, Brasil
}

$17^{\circ}$ Ergodesign - Congresso Internacional de Ergonomia e Usabilidade de Interfaces Humano Tecnológica: Produto, Informações Ambientes Construídos e Transporte $17^{\circ}$ USIHC - Congresso Internacional de Ergonomia e Usabilidade de Interfaces Humano Computador

\begin{abstract}
The Brazilian educational system has taken higher education to places increasingly distant from the capitals. Universities have been a reality now accessible in less developed urban cities in the interior of the country. The locations of educational centers are not always provided with commercial establishments in their surroundings, compromising the permanence of students and teachers for long periods of time on campus. In this sense, the current research presents an ergonomic analysis of the adaptation of part of a singlefamily residence in the only popular restaurant in the vicinity of a relatively recent university campus in a northeastern inner city. The methodology used consisted of applying stages of the Methodology for Human Centered Construction Projects. The research allowed the identification of several points of inadequacy, which compromise the quality of the activity, as well as the safety of users in space. From the results of the analysis was presented a list of ergonomic recommendations and a proposal for a new layout that would meet all the suggested changes.
\end{abstract}

Ergonomic analysis, Residential adaptation, Ergonomics recommendations.

\section{INTRODUÇÃO}

O desenvolvimento da educação no Brasil tem sido marcado pela difusão de novos estabelecimentos de ensino. O ensino superior cresceu consideravelmente nos últimos 10 anos e novos campus universitários tem sido instalados ao logo de todo o país. Muitos destes centros universitários tem buscado o crescimento de regiões mais afastadas das capitais, levando o conhecimento ao interior dos Estados, com isso, desenvolve-se as pequenas cidades e, consequentemente, todo o país.

Muitas das cidades selecionadas para abrigarem novos campus universitários, ainda não se encontram em um nível de desenvolvimento urbano tão avançado quanto nas capitais, o que faz com que, somado à necessidade de procura por terrenos de grande dimensão, se instale campus em áreas pouco urbanizadas e com poucos pontos comerciais no entorno da instituição de ensino. Este fato ocorreu com o estudo de caso realizado na corrente pesquisa. O campus foi instalado em uma grande área, a qual não possui muitos pontos comerciais na malha urbana das do entorno do terreno. Apenas um restaurante pode ser encontrado próximo às instalações da instituição e este é uma adaptação de uma residência unifamiliar. Para a adaptação da edificação, os proprietários do estabelecimento isolaram parte do pavimento térreo, bem como a garagem e, nestes espaços, construíram uma cozinha e distribuíram mesas e cadeiras.

Tomando como referência o contexto no qual se situa a edificação, a corrente pesquisa visou analisar possíveis pontos de inadequação ergonômica, bem como apresentar uma lista de recomendações e uma proposta de leiaute que promova o conforto no desempenho das atividades no local. A investigação repousou o foco na área de refeições do restaurante familiar, a qual é utilizada por estudantes, professores e moradores da região.

\section{FUNDAMENTAÇÃO TEÓRICA}

A construção de edificações multifuncionais sempre existiu, entretanto teve o seu grande desenvolvimento no final do século XIX, quando houve um crescimento da densidade populacional nas cidades em consequência da revolução industrial e das evoluções técnicas. A escassez de terrenos nas áreas urbanas, o seu elevado valor, a pressão imobiliária e os 
avanços tecnológicos, potenciaram o crescimento. Passou a existir uma necessidade de sobreposição de funções e, deste modo, as primeiras edificações multifuncionais, tal como as conhecemos, nasceram nas grandes áreas metropolitanas (FERREIRA, 2012). A autora destaca que, devido ao seu carácter único, pelas grandes áreas de construção envolvidas, pela necessidade do seu grande desenvolvimento horizontal ou em altura a que acrescem a sobreposição de usos e funções a eles associados, estávamos perante um novo tipo de edifício, a edificação híbrida.

Diversos estudos têm apontado a existência de riscos presentes nessa atividade produtiva, tais como ruído excessivo, instrumentos mal planejados que exigem a adoção de posturas inadequadas, realização de movimentos repetitivos e esforço físico excessivo, além de outros "fatores relacionados à organização do trabalho, como ritmo e esforço de trabalho intensos, [...] número insuficiente de trabalhadores, normas e práticas exigidas" (COLARES, 2007; CARVALHO, 2009; MONTEIRO et al., 2014).

A alimentação coletiva é um setor em progresso e que movimenta a economia do Brasil, pois além de possuir alto faturamento, produz muitas refeições diárias e emprega muitas pessoas (GORGULHO; LIPI; MARCHIONI, 2011). Apesar de dispor de equipamentos em quantidade significativa, a qualidade das refeições está diretamente relacionada ao desempenho da mãode-obra (MATOS; PROENÇA, 2003). De tal maneira, as condições físicas e ambientais das unidades de alimentação e nutrição (UAN) devem ser adequadas para que o trabalhador do setor de produção de refeições consiga manter a qualidade do produto e do serviço oferecido (IIDA, 2005).

\section{METODOLOGIA}

Como guia de procedimentos investigativos para o desenvolvimento da corrente pesquisa, lançou-se mão da Metodologia para Projetos de Construção Centrados no Usuário, desenvolvida pelas autoras Attaianese e Duca (2012). Esta metodologia consiste, em sua essência, em fornecer caminhos para a concepção do projeto de um ambiente centrado no ser humano. O processo é caracterizado pela formação de sete etapas, porém, neste estudo, apenas as cinco primeiras 5 foram comtempladas. Esta seleção destas etapas deve-se ao fato de que, para realização das duas últimas fases, é necessário que a edificação esteja construída, o que não ocorreu até o momento de composição deste artigo. Sendo assim, as cinco etapas contempladas foram: Briefing de Design, Perfis de Usuários e Grupos de Ajuste, Análise da Tarefa, Adaptação as necessidades dos usuários e Primeiros Detalhes Arquitetônicos.

O objeto de análise tratou-se de um restaurante familiar localizado em uma cidade do interior do nordeste brasileiro, estabelecido em uma residência unifamiliar. O espaço abre ao público nos dias úteis, entre às $11 \mathrm{~h} 30 \mathrm{~min}$ e $13 \mathrm{~h} 30 \mathrm{~min}$ e atua no mercado local desde abril de 2015 . 0 restaurante é frequentado, principalmente, por colaboradores e alunos de estabelecimentos próximos. O foco do estudo está no espaço dedicado a disposição das mesas, da bancada de trabalho e do buffet. A edificação é constituída por dois pavimentos, no térreo encontra-se o ponto comercial e no pavimento superior a residência onde moram os proprietários do restaurante. 


\section{RESULTADOS}

\subsection{Briefing de Design}

A construção possui dois pavimentos: o térreo, área voltada ao restaurante e o primeiro pavimento onde é localizada a residência dos proprietários. O espaço do restaurante é composto por quatro áreas: cozinha, banheiros, área interna e área externa. As áreas abordadas nessa pesquisa foram as utilizadas pelos clientes do restaurante durante a refeição: área externa (local das mesas principais) e área interna (área do buffet e caixa). Na área externa (Figura 01), estão alocadas quatro mesas pequenas de mesmo modelo, com espaço para acomodação de quatro pessoas, e uma mesa grande, com espaço para seis pessoas.

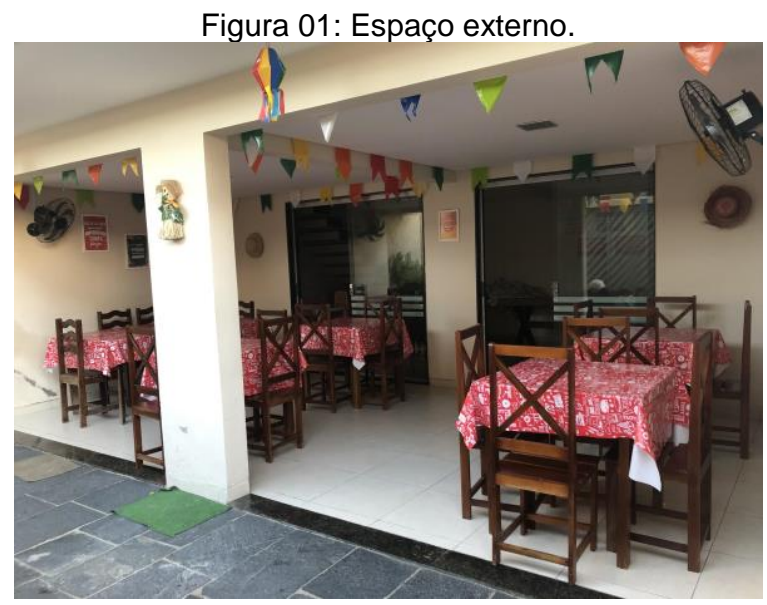

Fonte: Capturado pelos autores (2019).

O leiaute do espaço interno (Figura 02), é composto pelo caixa, frigobar, bancada do buffet, três mesas de plástico dispostas no ambiente e nove banquinhos, distribuídos entre as mesas.

Figura 02: Espaço interno.

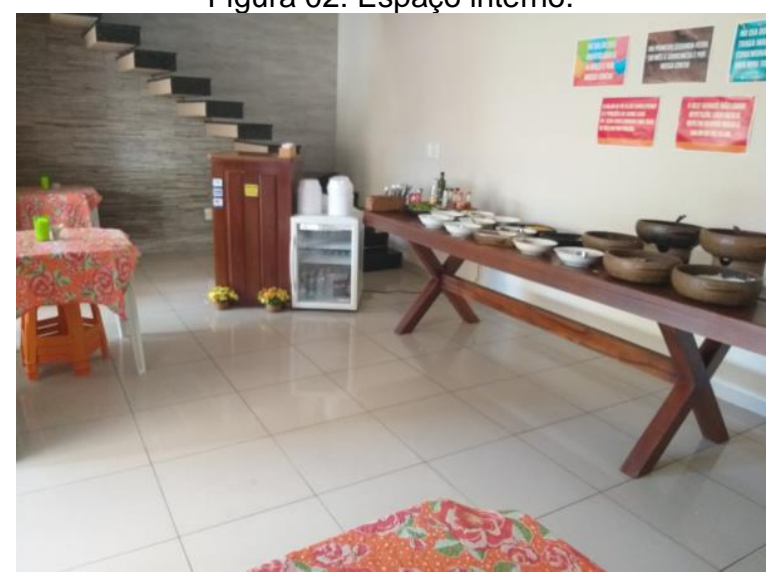

Fonte: Capturado pelos autores (2019).

O espaço sob a escada (Figura 03) é utilizado para a acomodação de uma mesa de plástico e armazenamento das mesas reservas. 
Figura 03: Espaço sob escada.

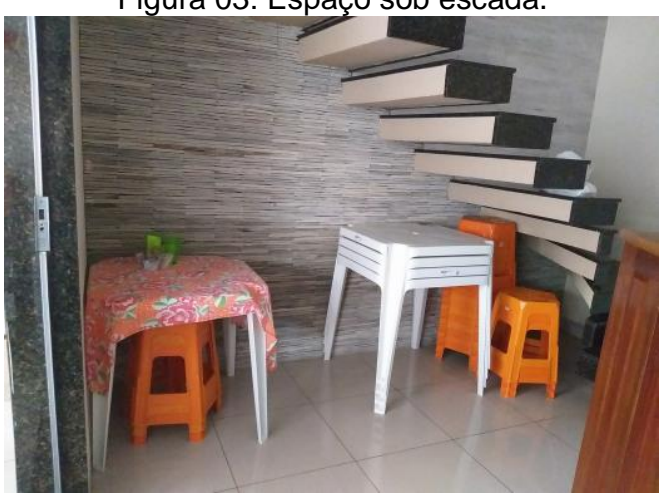

Fonte: Capturado pelos autores (2019).

No espaço da bancada do buffet, o fluxo de funcionários é intenso em decorrência da demanda de reposição dos produtos, além de todos enfrentarem dificuldades quanto a circulação entre essas áreas (Figura 04).

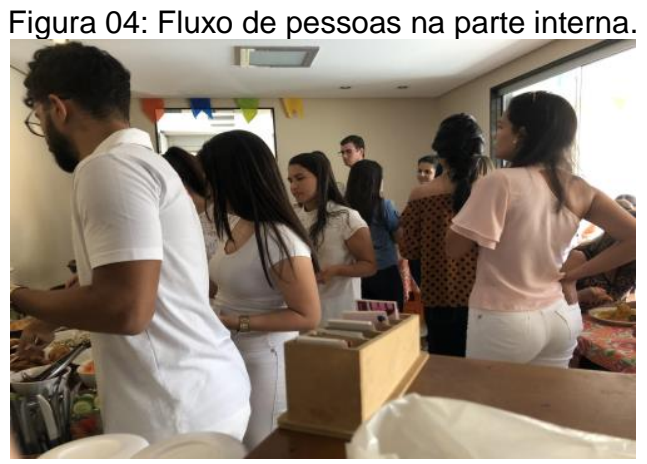

Fonte: Capturado pelos autores (2019).

O leiaute do ambiente é moldado pela demanda dos usuários, que varia de acordo com dia e época do mês e ano. O horário de funcionamento do restaurante acontece no período de maior incidência solar, o portão feito de alumínio (Figura 05), absorve todo o calor.

Figura 05: Portão de entrada.

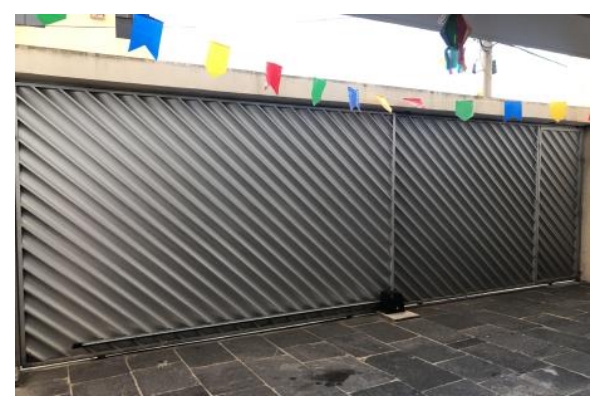

Fonte: Capturado pelos autores (2019).

A divisão entre os ambientes interno e externo é feita por duas portas corrediças de vidro (Figura 06), elas são mantidas abertas durante o horário de funcionamento. Mesmo tendo 
faixas de identificação, ocorrem acidentes pela dificuldade de visualizar as portas, principalmente no público idoso, pois as faixas não possuem grande contraste.

Figura 06: Portas de vidro. Fonte: Capturado pelos autores (2019).

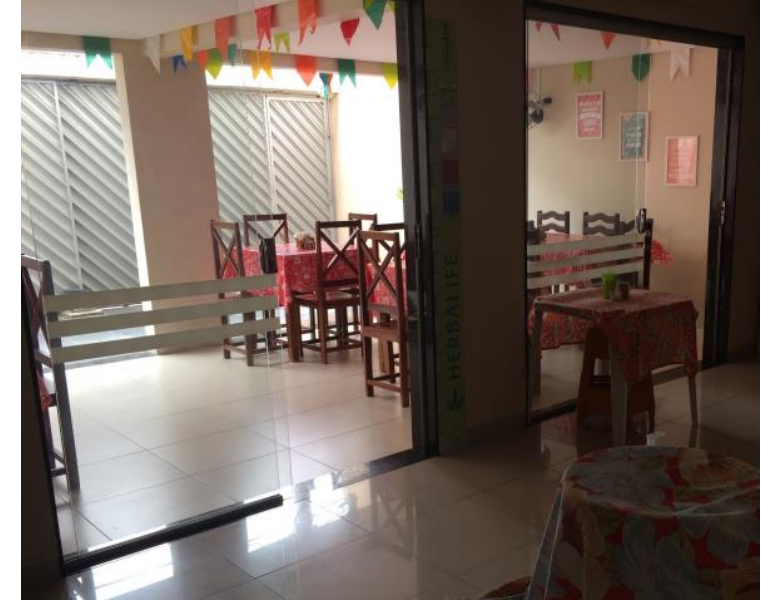

Com a organização interna, o caixa (Figura 07) fica disposto ao lado do frigobar, na área o funcionário responsável pelo caixa está constantemente exposto ao risco de queimadura devido as serpentinas da grade de energia do frigobar, além do risco de tropeçar no fio da tomada.

Figura 7: Caixa e frigobar. Fonte: Capturado pelos autores (2019).

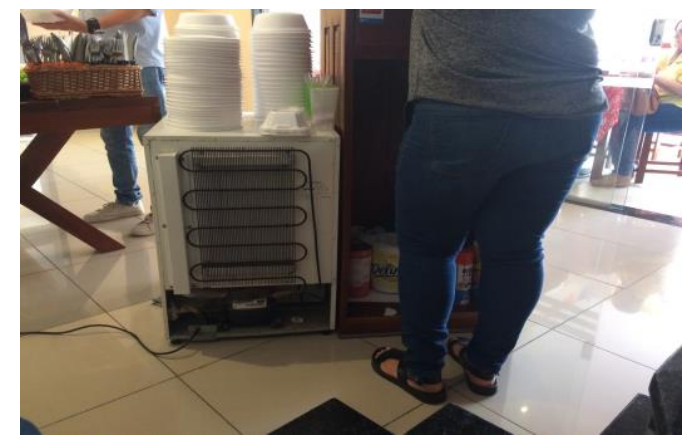

A má distribuição de cores pode afetar o cognitivo humano, o excesso de cores neutras e a ausência de uma alternância cromática, pode transmitir o sentimento de monotonia e tédio dentro do ambiente.

\subsection{Perfis de Usuários e Grupos de Ajuste}

Aproximadamente 70 indivíduos com dimensões corpóreas e idades que variam entre 3 e 80 anos frequentam diariamente o ambiente, incluindo idosos que apresentam mobilidade física reduzida. O restaurante possui 3 funcionários, com idade entre 21 e 43 anos. Todos os colaboradores pertencem ao gênero feminino, com estaturas que variam entre $1,55 \mathrm{~m}$ a 1,69m, e peso entre $55 \mathrm{~kg}$ a $86 \mathrm{~kg}$. Nenhum dos funcionários possui restrições de mobilidade. 
Para análise da fundamentação psicofisiológica dos usuários, foram considerados aspectos e características predominantes aos consumidores. A maioria dos clientes não apresenta restrições que impossibilitam a utilização do espaço, no entanto há um seleto grupo que enfrenta certa dificuldade. Usuários com menos de 1,20m apresentam dificuldade em servir-se na bancada, assim como os idosos que apresentam mobilidade física reduzida.

\subsubsection{Configuração da edificação doente}

Os procedimentos tomados envolveram a análise de campo, com intuito de estudar a interação do usuário com o ambiente, visando o conforto ao meio. Nesta etapa, detalhou-se os elementos do ambiente (quadro 01).

Quadro 01: Estrutura do ambiente. Fonte: Elaborado pelos autores (2019).

\begin{tabular}{|c|c|}
\hline \multicolumn{2}{|r|}{ AREA DE REFEIÇOES DO RESTAURANTE } \\
\hline Atributos & Elementos Arquitetônicos \\
\hline Geometria & Retangular \\
\hline Dimensões & $\begin{array}{l}\text { Area de Piso: } 51,30 \mathrm{~m}^{2} \\
\text { Área Coberta: } 57,80 \mathrm{~m}^{2}(51,30 \mathrm{~m} \text { da área de piso que é coberta }+6,50 \mathrm{~m} \text { de uma } \\
\text { marquise) } \\
\text { P.D: } 2,50 \mathrm{~m} \\
\text { Distância entre cadeiras: Variável. } \\
\text { Circulação principal: } 1,43 \mathrm{~m}\end{array}$ \\
\hline Esquadrias & $\begin{array}{l}\text { PORTAO PRINCIPAL: } \\
\text { Portão de correr em alumínio na cor prata, com tamanho de } 6,50 \mathrm{~m} \text { e } 2,10 \mathrm{~m} \text { de } \\
\text { altura. } \\
\text { ESQUADRIAS DE VIDRO: } \\
\text { Duas esquadrias de correr em alumínio e vidro. Uma com largura de } 2,00 \mathrm{~m} \text { e } \\
\text { outra com 1,70m de largura. Ambas possuem } 2,10 \mathrm{~m} \text { de altura. }\end{array}$ \\
\hline Leiaute & $\begin{array}{l}\text { AREA INTERNA: } \\
\text { Composto pela mesa principal (buffet), circulação dos funcionários: } 0,39 \mathrm{~m} \text {; } \\
\text { bancada do caixa; frigobar; três mesas e sete banquinhos de plástico. } \\
\text { ÁREA EXTERNA: } \\
\text { Apresenta a locação de quatro conjuntos de mesa com quatro locais, cada é } \\
\text { uma mesa contendo seis lugares. A menor distância entre as mesas possui } \\
0,13 \mathrm{~m} \text {. }\end{array}$ \\
\hline Revestimentos & $\begin{array}{l}\text { PISO: Cerâmica branca, com medida de } 0,40 \mathrm{~m} \times 0,40 \mathrm{~m} \text {, rejunte na cor cinza. } \\
\text { PAREDE: Parede em alvenaria, rebocada, emassada e pintada na cor areia; } \\
\text { TETO: Revestido em gesso, pintado na cor branco gelo. } \\
\text { CORES: } \\
\text { AMBIENTE EXTERNO } \\
\text { Em geral, o ambiente é bege e branco o que contrasta é a cor do mobiliário, que } \\
\text { é marrom por ser feito em madeira natural envernizada, e as toalhas das mesas } \\
\text { que possuem a cor vermelha. Também é possível identificar a cor preta nos } \\
\text { batentes e no portal entre os dois ambientes; } \\
\text { AMBIENTE INTERNO } \\
\text { Também possui predominância do bege e do branco, destacando somente a cor }\end{array}$ \\
\hline
\end{tabular}




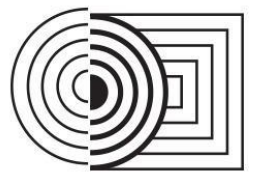

$17^{\circ}$ ERGODESIGN \& USIHC 2019

PUC-Rio, 11 a 13 de dezembro

Rio de Janeiro, RJ, Brasil $17^{\circ}$ Ergodesign - Congresso Internacional de Ergonomia e Usabilidade de Interfaces Humano Tecnológica: Produto, Informações Ambientes Construídos e Transporte $17^{\circ}$ USIHC - Congresso Internacional de Ergonomia e Usabilidade de Interfaces Humano Computador

\begin{tabular}{|c|c|}
\hline & $\begin{array}{l}\text { da madeira na mesa do buffet e do caixa, e o laranja dos banquinhos e das } \\
\text { toalhas das mesas de plástico. Assim como na área externa, é perceptível a } \\
\text { presença do preto, no revestimento dos degraus da escada e no portal de } \\
\text { acesso à cozinha. }\end{array}$ \\
\hline Mobiliário & 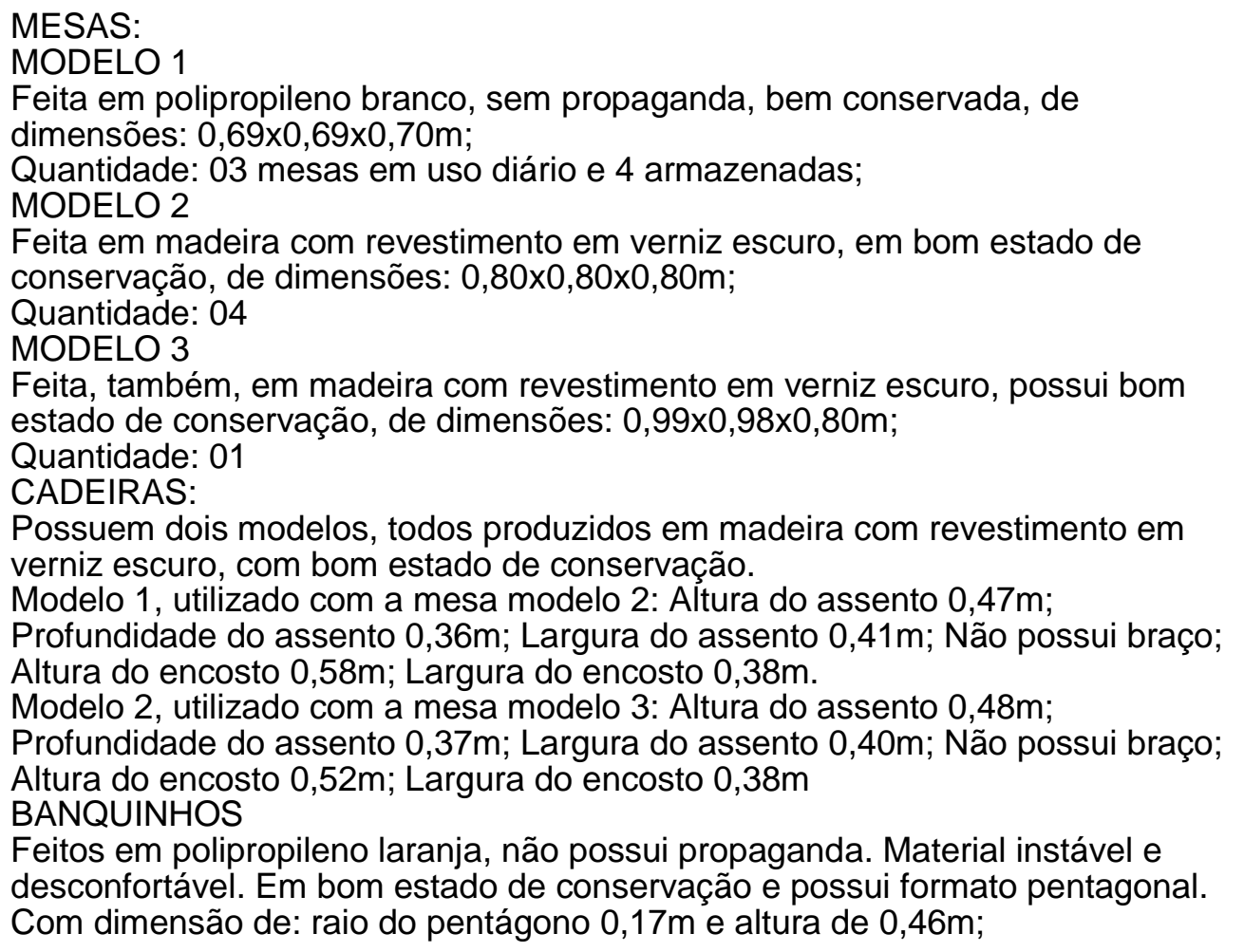 \\
\hline Acessibilidade & $\begin{array}{l}\text { Circulação Central: } 1,43 m(\text { Quando organizada, não atende a um cadeirante, } \\
\left.\text { sem possibilidade de giro } 360^{\circ}\right) \text {; } \\
\text { Circulação periférica: Não possui; } \\
\text { Mobiliário: Inadequado. Inexistência de mobiliário acessível ou espaço para } \\
\text { posicionamento do cadeirante; } \\
\text { Sinalização: Inexistente. }\end{array}$ \\
\hline Equipamentos & $\begin{array}{l}\text { AREA EXTERNA: } \\
\text { Instalação elétrica: duas luminárias de embutir com vidro leitoso, com lâmpadas } \\
\text { de luz branca (fria) e a instalação de dois ventiladores de parede. } \\
\text { ÁREA INTERNA: } \\
\text { Instalação elétrica: duas luminárias de embutir com vidro leitoso, com lâmpadas } \\
\text { na cor branca e oito pontos de iluminação focal, com lâmpadas na cor amarela. }\end{array}$ \\
\hline Suporte Social & $\begin{array}{l}\text { O restaurante é localizado em um bairro residencial o que proporciona um local } \\
\text { calmo e reservado. Por ser um ambiente familiar, também, oferece ao usuário } \\
\text { uma experiência única de acomodação e pertencimento. }\end{array}$ \\
\hline
\end{tabular}




\subsection{Análise da Tarefa}

As tarefas dos usuários diretos (funcionários) foram divididas em dois fluxogramas. O primeiro (Figura 08) retrata a atividade de checagem e reposição da bancada do buffet.

Figura 08: Tarefa de reposição. Fonte: Desenvolvido pelos autores (2019).

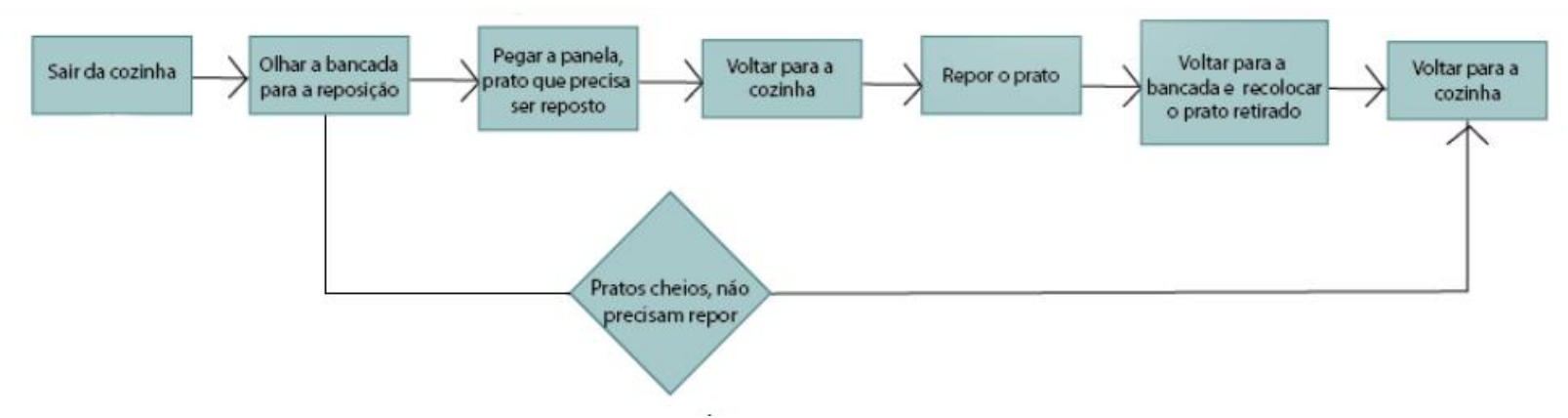

O esquema estabelecido para a distribuição das bebidas (Figura 09). O cliente faz o pedido referente ao que deseja e do caixa o funcionário passa a informação para os outros na cozinha. A entrega das bebidas é executada pelos colaboradores que administram a cozinha.

Figura 09: Tarefa de servir das bebidas. Fonte: Desenvolvido pelos autores (2019).

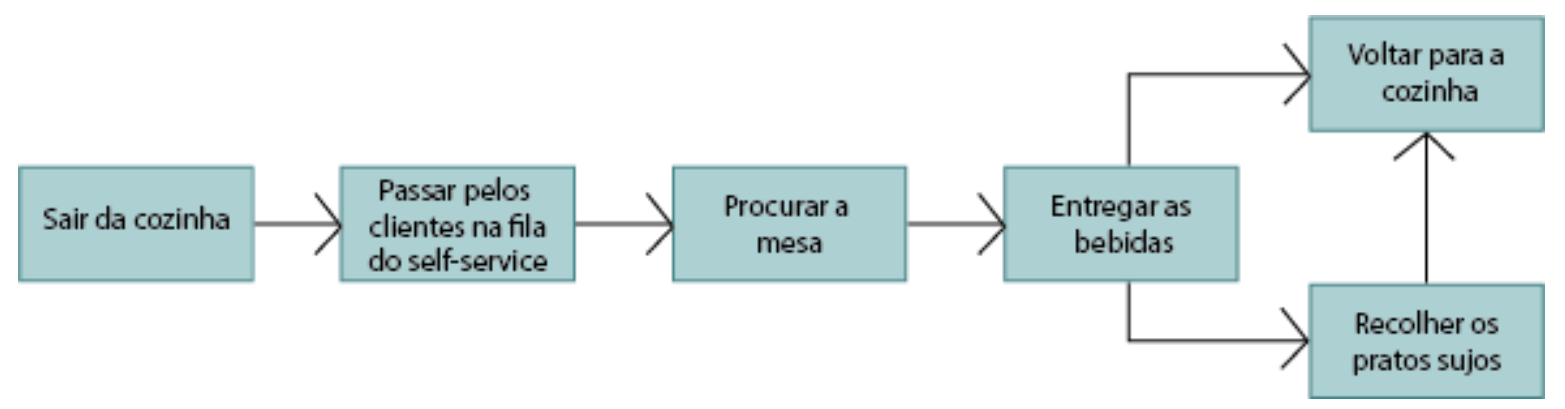

A tarefa de montar o prato (Figura 10), ao chegar no local o cliente deve se dirigir a bancada do buffet, em seguida para o caixa onde é feito o pedido da bebida ou segue para a acomodação nas mesas. Por fim, volta ao caixa para o pagamento do serviço prestado.

Figura 10: Tarefa dos clientes, self-service. Fonte: Desenvolvido pelos autores (2019).

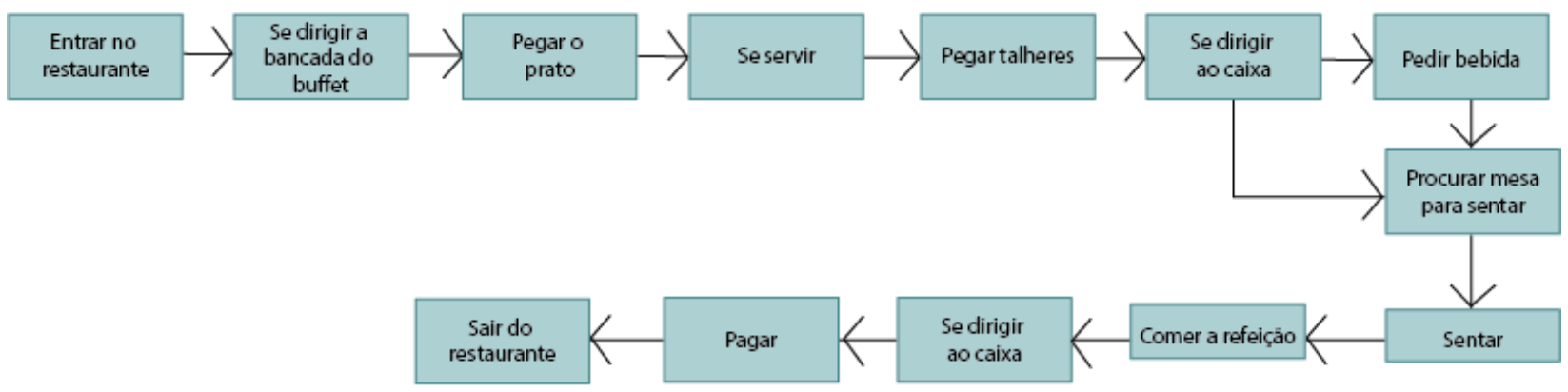


Outra opção de serviço é o preparo de marmitas para viagem (Figura 11). Antes de se dirigir a bancada o usuário deve ir até o caixa para a escolher entre as opções de embalagem, em seguida segue para a bancada iniciando a montagem da marmita. Finalização da compra ocorre no caixa, que segue o fluxo do final da bancada.

Figura 11: Tarefa dos clientes, marmita. Fonte: Desenvolvido pelos autores (2019).

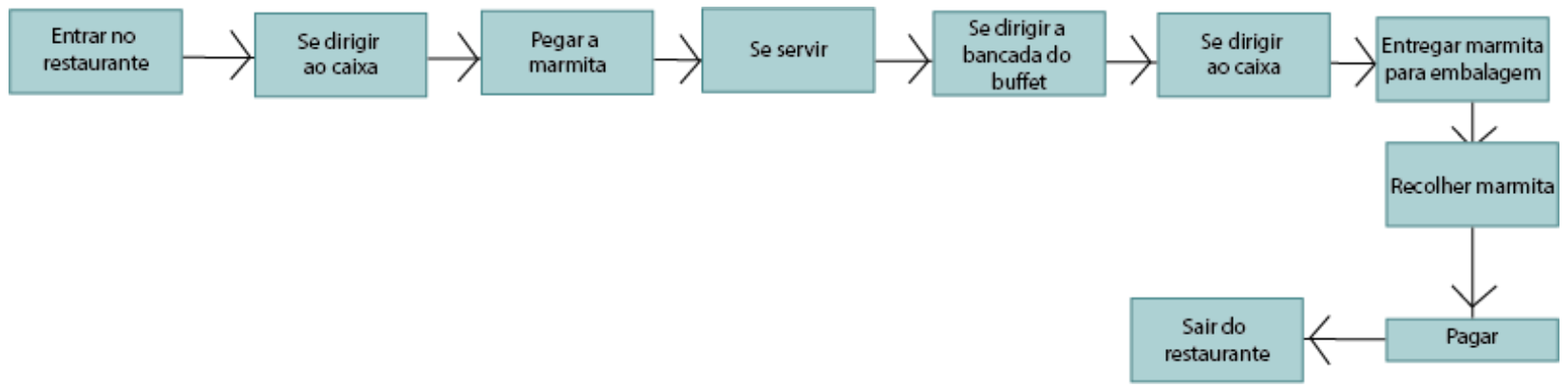

\subsubsection{Considerações sobre as posturas corporais}

Para a utilização do espaço o usuário é forçado a assumir posturas que podem prejudicar a sua integridade física, se assumidas por um determinado período de tempo e/ou frequência.

Devido à altura inadequada da mesa e assento da cadeira, o usuário é imposto a utilizar uma postura cifótica da coluna vertebral, ajustando seu corpo ao mobiliário (Figura 12).

Figura 12: Utilização do ambiente externo. Fonte: Desenvolvido pelos autores (2019).

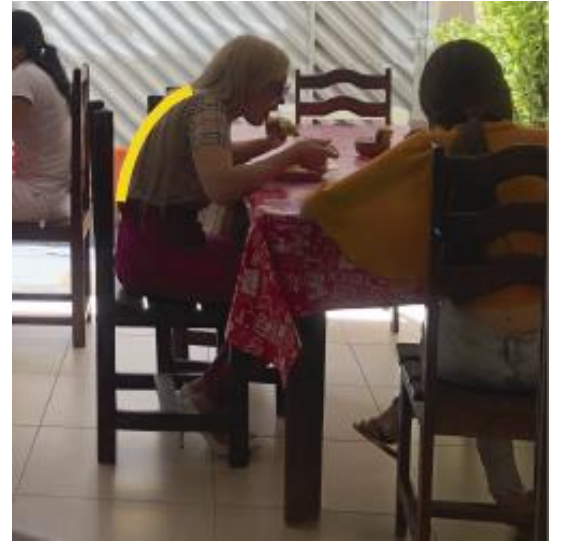

No momento em que as colaboradoras estão servindo a comida na bancada (Figura 13), elas assumem posturas fletidas de tronco, os ombros e a elevação dos membros superiores como forma de encontrar equilíbrio. 
Figura 13: Reposição do buffet. Fonte: Desenvolvido pelos autores (2019).

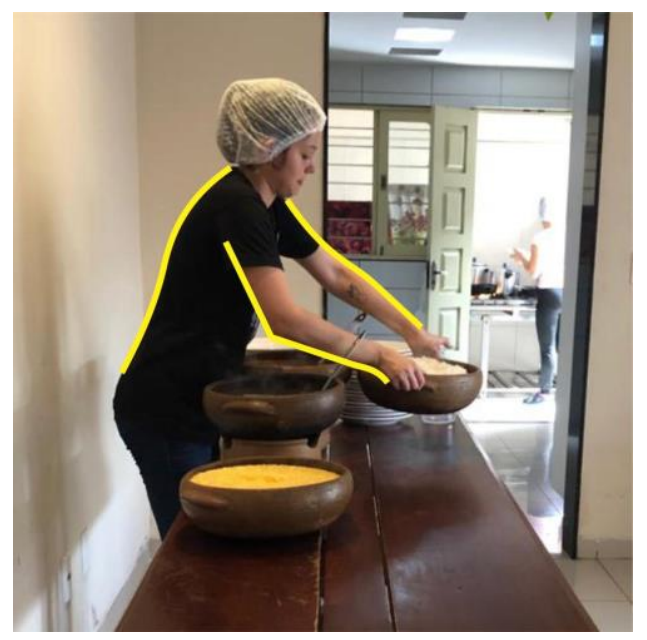

O funcionário do caixa fica de pé durante todo o horário de funcionamento (Figura 14). Também é exigido uma elevação dos membros superiores, ocorrendo pressão do antebraço na aresta da bancada. Longos períodos na posição de pé é extremamente fatigante, pois exige muito esforço da musculatura envolvida (trabalho estático).

Figura 14: Postura adotada no caixa. Fonte: Desenvolvido pelos autores (2019).

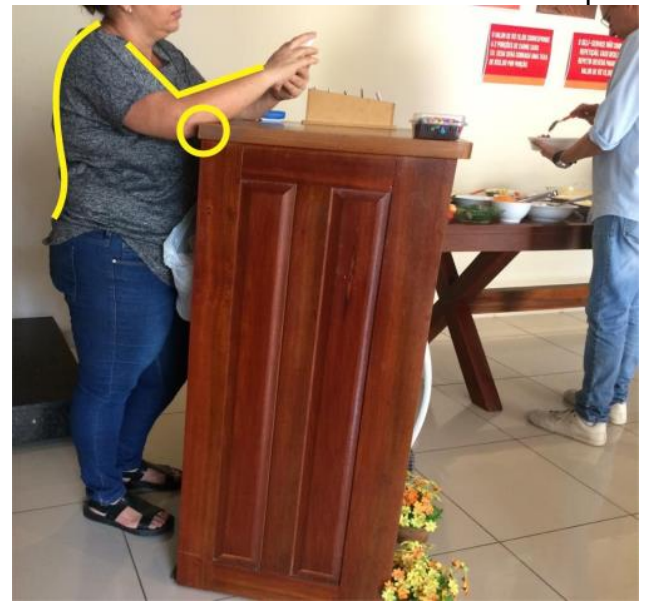

Vê-se que a má postura dos usuários está relacionada principalmente ao mobiliário inadequado, colocando em risco a integridade física do indivíduo.

\subsubsection{Considerações antropométricas}

O restaurante conta com três modelos distintos de mesas (Figura 15) nos dois espaços do ambiente analisado.. 


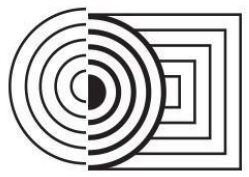

\section{$17^{\circ}$ ERGODESIGN \& USIHC 2019 \\ PUC-Rio, 11 a 13 de dezembro \\ Rio de Janeiro, RJ, Brasil}

$17^{\circ}$ Ergodesign - Congresso Internacional de Ergonomia e Usabilidade de Interfaces Humano Tecnológica: Produto, Informações Ambientes Construídos e Transporte

$17^{\circ}$ USIHC - Congresso Internacional de Ergonomia e Usabilidade

de Interfaces Humano Computador

Figura 15: Mesas Modelo 01, 02 e 03 respectivamente. Fonte: Capturado pelos autores (2019).

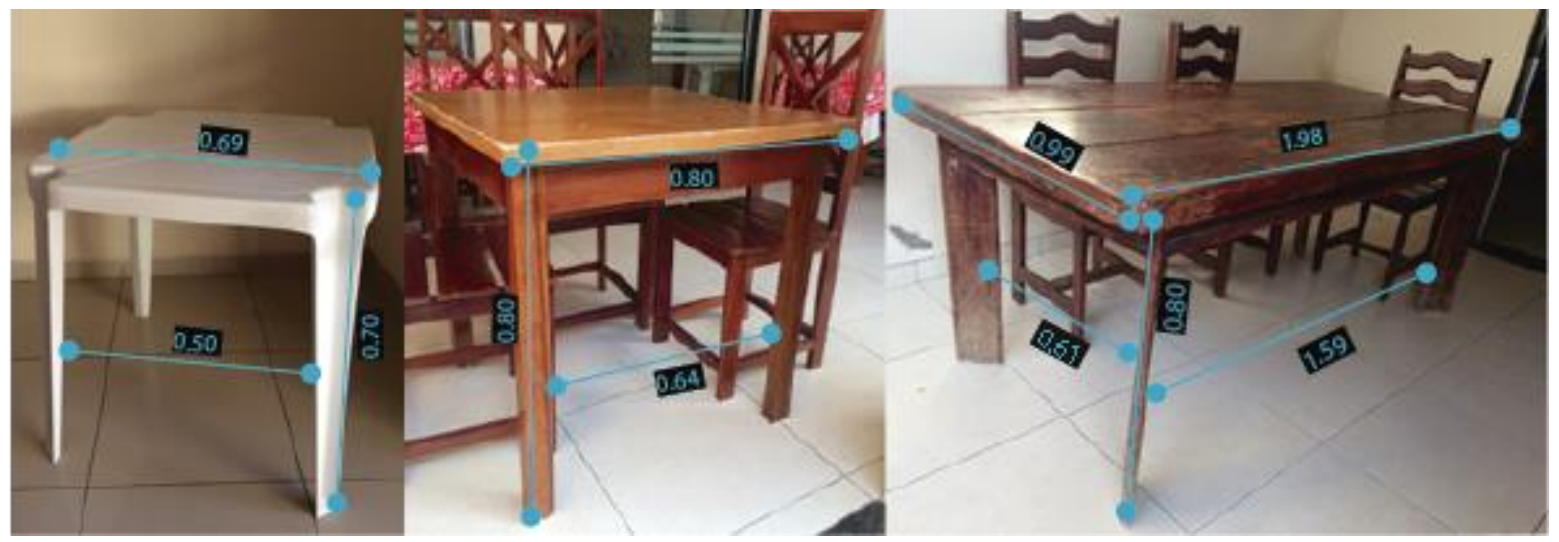

O mobiliário presente no espaço apresenta medidas diferentes entre si, como a variação na dimensão dos tampos e o espaço entre as pernas das mesas (quadro 02).

Quadro 02: Análise comparativa e situação dos modelos. Fonte: Desenvolvido pelos autores, adaptado de Panero e Zelnik, 2002; (2019).

\begin{tabular}{|l|c|c|c|c|c|}
\hline Dimensões & Modelo 01 & Modelo 02 & Modelo 03 & Recomendado & Situação \\
\hline Largura do tampo & $0,69 \mathrm{~m}$ & $0,80 \mathrm{~m}$ & $0,99 \mathrm{~m}$ & 0,762 & $\begin{array}{c}\text { Modelo } 01 \\
\text { Inadequado }\end{array}$ \\
\hline $\begin{array}{c}\text { Profundidade do } \\
\text { tampo }\end{array}$ & $0,69 \mathrm{~m}$ & $0,80 \mathrm{~m}$ & $1,98 \mathrm{~m}$ & $0,762 \mathrm{~m}-101,6 \mathrm{~m}$ & $\begin{array}{c}\text { Modelos } 02 \\
\text { Adequado }\end{array}$ \\
\hline Altura da mesa & $0,70 \mathrm{~m}$ & $0,80 \mathrm{~m}$ & $0,80 \mathrm{~m}$ & $0,731 \mathrm{~m}-0,762 \mathrm{~m}$ & Inadequado \\
\hline $\begin{array}{c}\text { Distância entre as } \\
\text { pernas }\end{array}$ & $0,50 \mathrm{~m}$ & $0,64 \mathrm{~m}$ & $0,61 \mathrm{~m}$ & $0,54 \mathrm{~m}-0,55 \mathrm{~m}$ & $\begin{array}{c}\text { Modelo1 } \\
\text { Inadequado }\end{array}$ \\
\hline
\end{tabular}

No ambiente estão disponíveis dois tipos de cadeiras e um modelo de banquinho (figura 16). As cadeiras não apresentam inclinação no encosto, sendo ele projetado em exatos $90^{\circ}$.

Figura 16: Cadeiras modelos 01 e 02, e banco. Fonte: Capturado pelos autores (2019).

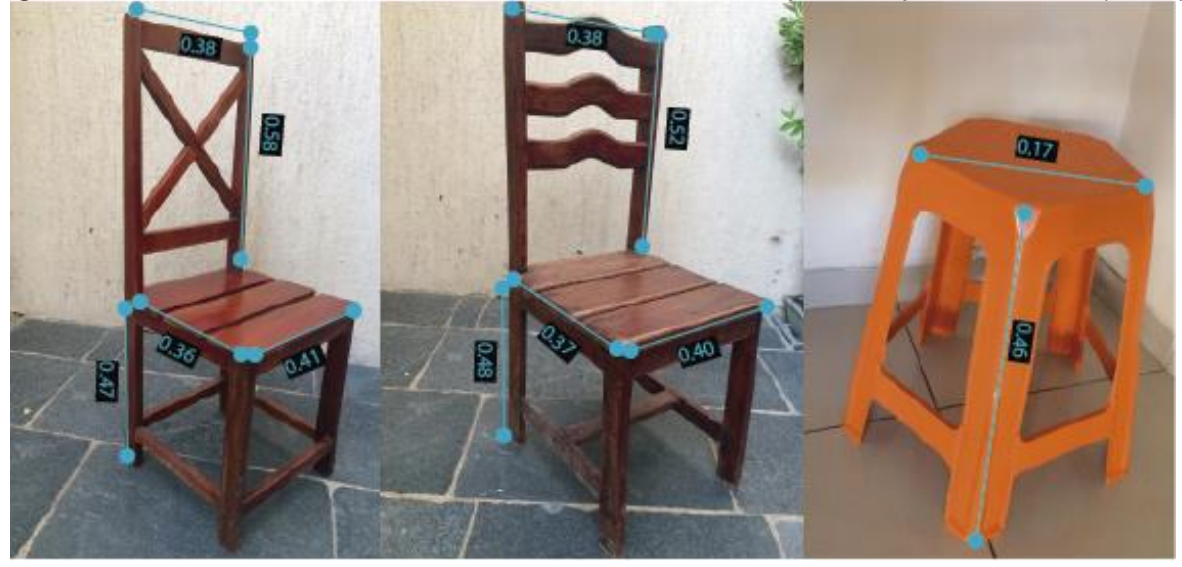


Foram analisadas as dimensões necessárias para a adequação do objeto às necessidades humanas, e a situação da mobília é de quase por completo inadequada (quadro 03).

Quadro 03: Análise comparativa e situação dos modelos. Fonte: Desenvolvido pelos autores, adaptado de Panero e Zelnik, 2013; Kroemer e Grandjean, 2005; lida, 2005; (2019).

\begin{tabular}{|c|c|c|c|c|c|}
\hline Dimensões & $\begin{array}{c}\text { Modelo } \\
01\end{array}$ & $\begin{array}{c}\text { Modelo } \\
02\end{array}$ & Banquinho & Recomendado & Situação \\
\hline $\begin{array}{c}\text { Altura do } \\
\text { assento }\end{array}$ & $0,47 \mathrm{~m}$ & $0,48 \mathrm{~m}$ & $0,46 \mathrm{~m}$ & $\begin{array}{c}0,406 \mathrm{~m}- \\
0,432 \mathrm{~m}\end{array}$ & Inadequado \\
\hline $\begin{array}{c}\text { Profundidade do } \\
\text { assento }\end{array}$ & $0,36 \mathrm{~m}$ & $0,37 \mathrm{~m}$ & Banco pentagonal & $\begin{array}{c}0,394 \mathrm{~m}- \\
0,406 \mathrm{~m}\end{array}$ & Inadequado \\
\cline { 1 - 1 } $\begin{array}{c}\text { Largura do } \\
\text { assento }\end{array}$ & $0,41 \mathrm{~m}$ & $0,40 \mathrm{~m}$ & com raio de 0,17m & $\begin{array}{c}0,406 \mathrm{~m}- \\
0,436 \mathrm{~m}\end{array}$ & $\begin{array}{c}\text { Modelo } 1 \\
\text { Adequado }\end{array}$ \\
\hline $\begin{array}{c}\text { Altura do } \\
\text { encosto }\end{array}$ & $0,58 \mathrm{~m}$ & $0,52 \mathrm{~m}$ & - & $0,43 \mathrm{~m}-0,61 \mathrm{~m}$ & Adequado \\
\hline $\begin{array}{c}\text { Largura do } \\
\text { encosto }\end{array}$ & $0,38 \mathrm{~m}$ & $0,38 \mathrm{~m}$ & - & $\begin{array}{c}0,457 \mathrm{~m}- \\
0,508 \mathrm{~m}\end{array}$ & Inadequado \\
\hline $\begin{array}{c}\text { Inclinação do } \\
\text { encosto }\end{array}$ & $90^{\circ}$ & $90^{\circ}$ & - & $95^{\circ}-105^{\circ}$ & Inadequado \\
\hline
\end{tabular}

Uma análise da circulação horizontal interna foi realizada com a utilização de modelos antropométricos aplicados em plantas baixa, já com leiaute. Esses modelos antropométricos foram apresentados em três cores: os verdes (circulação adequada); os amarelos (necessitam de atenção); e os vermelhos (áreas inadequadas). Manequins na cor cinza foram adicionados simulando as atividades estáticas.

Figura 17: Análise da circulação horizontal interna. Fonte: Elaborado pelos autores (2019).

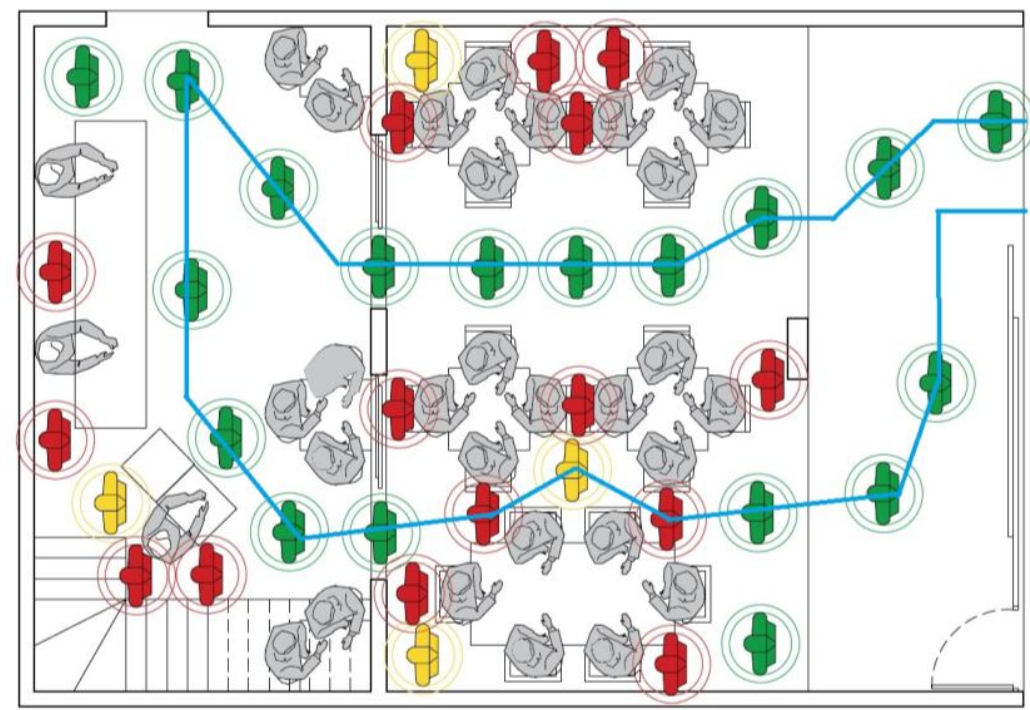


A análise permitiu notar que os espaços em situação adequada são os da circulação principal e a área do buffet. Os pontos inadequados mais críticos são os entre mesas, a área dos funcionários no buffet e a área do caixa.

Também foi feita a verificação para avaliar a acessibilidade do ambiente, como pode ser visto na figura 18.

Figura 18: Método MACHIA - acessibilidade. Fonte: Elaborado pelos autores (2019).

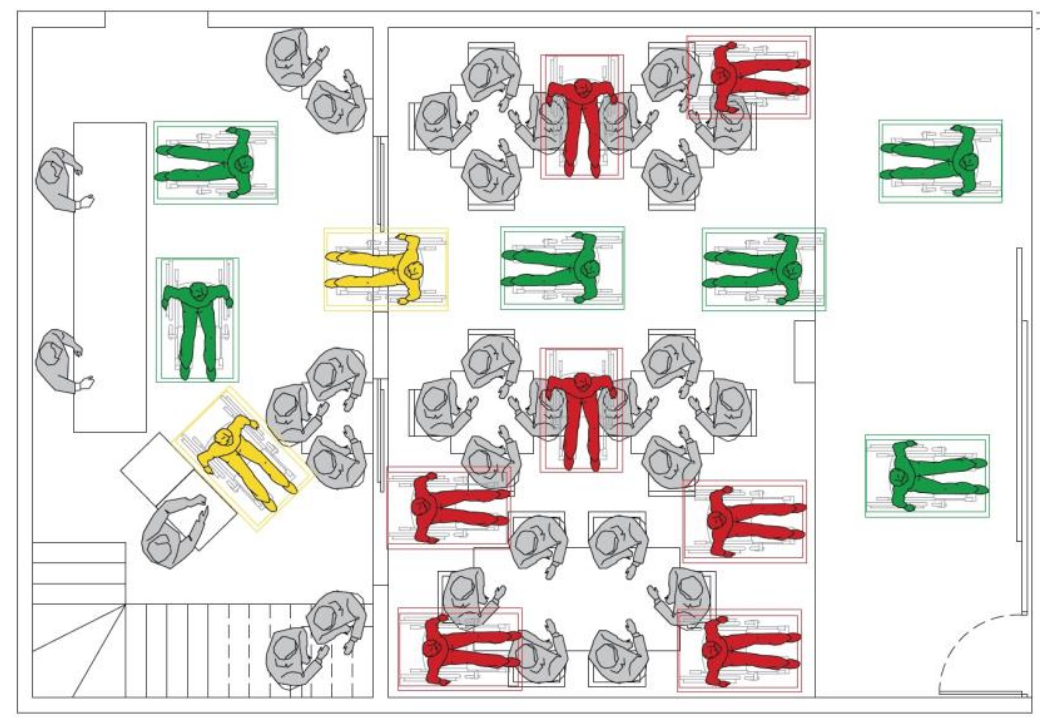

$\mathrm{Na}$ avaliação é possível notar que, apesar do cadeirante conseguir andar pelo corredor principal, ele terá dificuldade de realizar o giro de $360^{\circ}$, considerando a NBR9050:2015.

\subsubsection{Considerações sobre o conforto ambiental}

Para a verificação da iluminação, os parâmetros seguiram a NBR 5413:1992. Foram levados em consideração os parâmetros para um restaurante, entre 100 e 200 lux. As medições foram feitas com aparelho luxímetro digital portátil e verificadas em 11 pontos espalhados, já que a iluminação do local não é distribuída igualmente. Na parte interna as medidas foram nos pontos: $(A),(B),(C),(D),(E)$. No ambiente exterior as medidas foram retiradas nas seguintes localidades: $(F),(G),(H),(I),(J),(K),(L),(M),(N)$. 
Figura 19: Pontos de medição. Fonte: Elaborado pelos autores (2019).

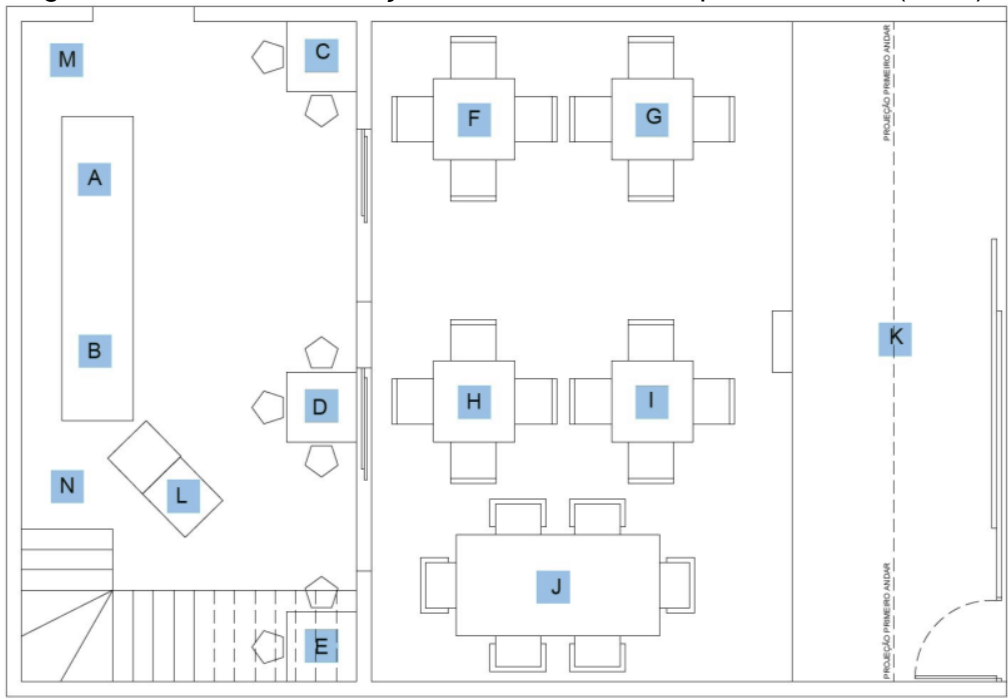

Na medição realizada durante o horário de funcionamento do restaurante, sem a influência de iluminação artificial, os resultados obtidos não estavam dentro do recomendado pela NBR 5413:1992 (quadro 04).

Quadro 04: Medição de lluminação. Fonte: Desenvolvido pelos autores (2019).

\begin{tabular}{|c|c|c|c|c|}
\hline Horário & Local & Medida em Lux & Recomendado & Situação \\
\hline \multirow{10}{*}{$\begin{array}{c}\text { Entre } 11: 30 \text { e } \\
12: 00 \\
\text { LÂMPADA } \\
\text { APAGADA }\end{array}$} & \multirow{2}{*}{$\begin{array}{c}\text { Bancada do } \\
\text { buffet }\end{array}$} & Ponto A: 178 lux & \multirow{10}{*}{$100 \operatorname{lux}-200 \operatorname{lux}$} & Adequado \\
\hline & & Ponto B: 260 lux & & Inadequado \\
\hline & Caixa & 268 lux & & Inadequado \\
\hline & Base da Escada & 262 lux & & Inadequado \\
\hline & Área descoberta & 1503 lux & & Inadequado \\
\hline & Mesa 01 & 165 lux & & Adequado \\
\hline & Mesa 02 & 189 lux & & Adequado \\
\hline & Mesa 03 & $42 \operatorname{lux}$ & & Inadequado \\
\hline & Mesa 04 & 353 lux & & Inadequado \\
\hline & Mesa 05 & 317 lux & & Inadequado \\
\hline
\end{tabular}




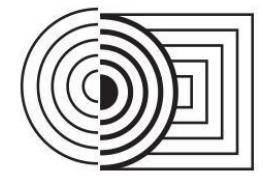

\section{$17^{\circ}$ ERGODESIGN \& USIHC 2019 \\ PUC-Rio, 11 a 13 de dezembro \\ Rio de Janeiro, RJ, Brasil}

$17^{\circ}$ Ergodesign - Congresso Internacional de Ergonomia e Usabilidade de Interfaces Humano Tecnológica: Produto, Informações Ambientes Construídos e Transporte

$17^{\circ}$ USIHC - Congresso Internacional de Ergonomia e Usabilidade

de Interfaces Humano Computador

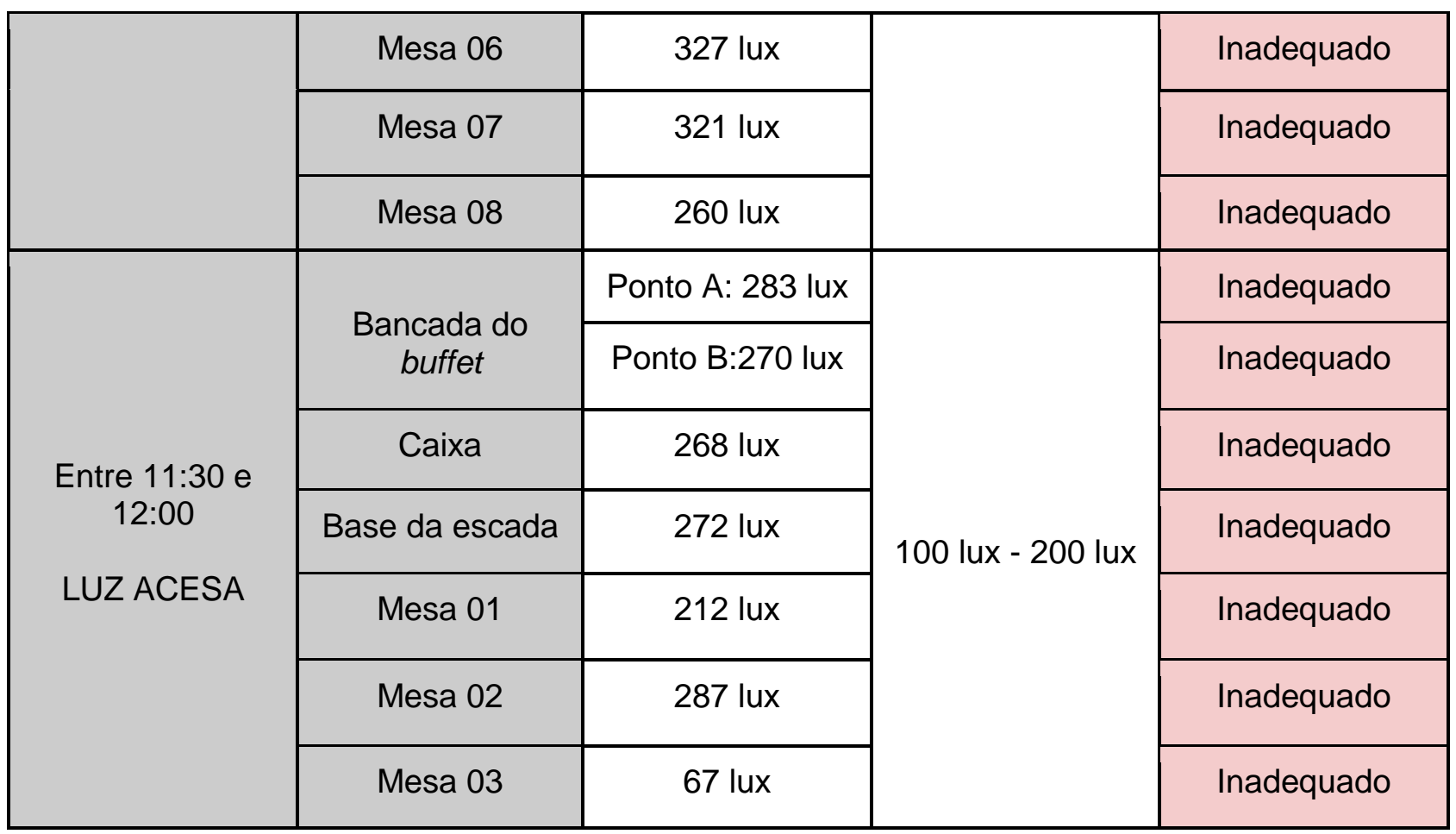

A temperatura do ambiente também foi verificada. De acordo com a medição realizada por termômetro digital, foi observada uma temperatura entre $28^{\circ} \mathrm{C}$ e $29.1^{\circ} \mathrm{C}$. As medições excedem o recomendado pela NR17:2007 e NBR16401-2, que indica um índice de temperatura efetiva entre $20^{\circ} \mathrm{C}$ e $23^{\circ} \mathrm{C}$.

Quadro 05: Medição de Temperatura. Fonte: Desenvolvido pelos autores (2019).

\begin{tabular}{|c|c|c|c|}
\hline Horário & Medida em ${ }^{\circ} \mathrm{C}$ & Recomendado & Situação \\
\hline Entre $11: 30$ e $12: 00$ & de $28^{\circ} \mathrm{C}$ à $28.2^{\circ} \mathrm{C}$ & de $20^{\circ} \mathrm{C}$ à $23^{\circ} \mathrm{C}$ & Inadequado \\
\hline Entre $13: 00$ e $13: 30$ & de $28.9^{\circ} \mathrm{C}$ à $29.1^{\circ} \mathrm{C}$ & de $20^{\circ} \mathrm{C}$ à $23^{\circ} \mathrm{C}$ & Inadequado \\
\hline
\end{tabular}

De acordo com a NR17:2007 e a NBR10152:1987 o nível máximo aceitável de ruído, é de $65 \mathrm{~dB}$. O ruído na área interna do restaurante alcançou a média de $74.2 \mathrm{~dB}$, apresentando picos de $91 \mathrm{~dB}$ e, na área externa, a média alcançou $77.4 \mathrm{~dB}$ e máxima de $90.6 \mathrm{~dB}$. Para a medição do ruído foi utilizado um decibelímetro digital, devidamente calibrado. 
Quadro 06: Medição de Ruído. Fonte: Desenvolvido pelos autores (2019).

\begin{tabular}{|c|c|c|c|}
\hline Horário & Medida em dB & Recomendado & Situação \\
\hline & ÁREA INTERNA & & \\
Entre $11: 30$ e 12:00 & $74.2 \mathrm{~dB}$ & & \\
Durante & máx: $91 \mathrm{~dB}$ & até $65 \mathrm{~dB}$ & \\
funcionamento do & ÁREA EXTERNA & & \\
restaurante & $77.4 \mathrm{~dB}$ & & \\
& máx: $90.6 \mathrm{~dB}$ & & \\
\hline
\end{tabular}

No que tange à ventilação, a NR17:2007 e a NBR16401-2 estabelece que a velocidade do ar não pode exceder $0,7 \mathrm{~m} / \mathrm{s}$. Na medição realizada no restaurante, a velocidade do ar na parte interna foi de $0.1 \mathrm{~m} / \mathrm{s}$ e na parte externa $1.3 \mathrm{~m} / \mathrm{s}$. Para a medição da ventilação foi utilizado um termo-anemômetro digital, devidamente calibrado.

Quadro 07: Medição de Ventilação/Aeração. Fonte: Desenvolvido pelos autores (2019).

\begin{tabular}{|c|c|c|c|}
\hline Horário & Medida em m/s & Recomendado & Situação \\
\hline \multirow{2}{*}{$\begin{array}{c}\text { Entre 11:30 e 12:00 } \\
\text { Maior número de }\end{array}$} & INTERNA & & Adequado \\
\cline { 2 - 4 } pessoas no ambiente & $0,1 \mathrm{~m} / \mathrm{s}$ & até $0,7 \mathrm{~m} / \mathrm{s}$ & Inadequado \\
& $\begin{array}{c}\text { EXTERNA } \\
1,3 \mathrm{~m} / \mathrm{s} \\
\text { (uso dos } \\
\text { ventiladores) }\end{array}$ & até $0,7 \mathrm{~m} / \mathrm{s}$ & \\
& & & \\
\hline
\end{tabular}

A respeito da análise da umidade do ambiente, a NR17:2007 indica que a umidade relativa do ar não esteja inferior a $40 \%$ e, de acordo com a medição realizada no ambiente, é possível notar que a área está dentro dos parâmetros já que a medição ficou em $52 \%$. Para a medição da umidade foi utilizado um termo-higrômetro digital, devidamente calibrado.

Quadro 08: Medição de Umidade. Fonte: Desenvolvido pelos autores (2019).

\begin{tabular}{|c|c|c|c|}
\hline Horário & Medida em & Recomendado & Situação \\
\hline Entre 11:30 e 12:00 & $52 \%$ & não inferior a $40 \%$ & Adequado \\
\hline
\end{tabular}

\subsection{Adaptação às Necessidades Dos Usuários}

\subsubsection{Recomendações ergonômicas}

No quadro 09 são apontados todos os problemas detectados na Área de Refeições ao longo desta pesquisa e, também, apresenta proposições ergonômicas para o espaço com o intuito de 


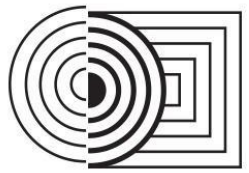

\section{$17^{\circ}$ ERGODESIGN \& USIHC 2019 \\ PUC-Rio, 11 a 13 de dezembro \\ Rio de Janeiro, RJ, Brasil}

$17^{\circ}$ Ergodesign - Congresso Internacional de Ergonomia e Usabilidade de Interfaces Humano Tecnológica: Produto, Informações Ambientes Construídos e Transporte $17^{\circ}$ USIHC - Congresso Internacional de Ergonomia e Usabilidade de Interfaces Humano Computador

corrigir os erros analisados, e servir de guia para o projeto de requalificação do ambiente.

Quadro 09: Diagnóstico e Proposições Ergonômicas Para o Ambiente. Fonte: Desenvolvido pelos autores (2019).

\begin{tabular}{|c|c|}
\hline DIAGNOSTICO & PROPOSIÇOES ERGONOMICAS \\
\hline Espaço pequeno para a demanda. & $\begin{array}{l}\text { Ampliar a área do ambiente para a área descoberta } \\
\text { do local. }\end{array}$ \\
\hline $\begin{array}{l}\text { Area descoberta sofre com exposição ao sol } \\
\text { e chuva. }\end{array}$ & Implantar uma coberta no local da área. \\
\hline $\begin{array}{l}\text { O portão de alumínio deixa o ambiente } \\
\text { quente. }\end{array}$ & Substituir o portão de entrada por um de madeira. \\
\hline $\begin{array}{l}\text { Mesas principais mal distribuídas dificultando } \\
\text { o espaço de circulação. }\end{array}$ & $\begin{array}{l}\text { Substituir por mesas retráteis para otimizar o } \\
\text { espaço de circulação dos clientes e funcionários. }\end{array}$ \\
\hline $\begin{array}{l}\text { Mobiliário interno com má distribuição, } \\
\text { impede o fluxo da cozinha para o ambiente } \\
\text { externo a depender da demanda. }\end{array}$ & $\begin{array}{l}\text { Realocar o mobiliário interno e replanejar o sentido } \\
\text { do fluxo, de forma que os usuários identifiquem a } \\
\text { entrada e saída sem a necessidade de cruzamento } \\
\text { de fluxos. }\end{array}$ \\
\hline Pouca iluminação interna. & $\begin{array}{l}\text { Implantar iluminação direcionada para a bancada } \\
\text { do buffet e caixa, e outra geral indireta e uniforme. }\end{array}$ \\
\hline $\begin{array}{l}\text { Mesas do ambiente interno, dificultam a } \\
\text { circulação e não são adequadas para a } \\
\text { utilização. }\end{array}$ & $\begin{array}{l}\text { Realocar as mesas para a área externa e implantar } \\
\text { novo mobiliário adequado para a demanda, de } \\
\text { acordo com os dados antropométricos. }\end{array}$ \\
\hline $\begin{array}{l}\text { Escada suspensa aberta para o público, } \\
\text { crianças costumam brincar entre os degraus. }\end{array}$ & $\begin{array}{l}\text { Bloquear acesso a escada suspensa por uma } \\
\text { parede de MDF customizada. }\end{array}$ \\
\hline Falta de sinalização indicativa. & $\begin{array}{l}\text { Implantar sinalização indicativa no ambiente para } \\
\text { melhorar a interação do usuário com o ambiente. }\end{array}$ \\
\hline $\begin{array}{l}\text { As portas de vidros se tornam obstáculos } \\
\text { entre os ambientes, dificultam a circulação e } \\
\text { visualização da área interna. }\end{array}$ & $\begin{array}{l}\text { Retirar as portas de vidro e substituir por portas de } \\
\text { rolo, para diminuir a quantidade de obstáculos } \\
\text { entre os ambientes. }\end{array}$ \\
\hline $\begin{array}{l}\text { Espaço de circulação entre a parede e } \\
\text { bancada do buffet não permite o livre } \\
\text { acesso dos funcionários. }\end{array}$ & $\begin{array}{l}\text { Ampliar espaço entre bancada e parede, } \\
\text { proporcionando mais espaço de movimentação } \\
\text { para os funcionários. }\end{array}$ \\
\hline Excesso de cores neutras no local. & $\begin{array}{l}\text { Alternar de forma harmônica entre pigmentos } \\
\text { quentes e neutros no ambiente. }\end{array}$ \\
\hline $\begin{array}{l}\text { Concentração de cores vivas em lugares } \\
\text { inadequados do espaço. }\end{array}$ & $\begin{array}{l}\text { Redistribuir e aplicar as cores (vermelho } \\
\text { alaranjado, amarelo em tom mais claro, marrom, } \\
\text { branco e marrom acinzentado) a fim de despertar } \\
\text { sensações como: mais apetite, aconchego e } \\
\text { vivacidade. }\end{array}$ \\
\hline Ausência de área verde. & $\begin{array}{l}\text { Inserir área verde no ambiente interno, com o } \\
\text { propósito de trazer bem-estar e aconchego para o }\end{array}$ \\
\hline
\end{tabular}




\begin{tabular}{|l|l|}
\hline & espaço. \\
\hline $\begin{array}{l}\text { Pouca acessibilidade para cadeirantes e } \\
\text { pessoas que necessitam de atendimento } \\
\text { especial. }\end{array}$ & $\begin{array}{l}\text { Redirecionar o fluxo de usuários para o formato em } \\
\text { "U”, oferecendo mobilidade para cadeirantes. }\end{array}$ \\
\hline Temperatura do ambiente é elevada. & Implantação de um sistema de climatizadores. \\
\hline Desnível no piso com pequenos batentes. & $\begin{array}{l}\text { Adicionar pequenas rampas para nivelar e } \\
\text { possibilitar o acesso de cadeirantes. }\end{array}$ \\
\hline $\begin{array}{l}\text { Acesso para a casa no pavimento superior } \\
\text { sem proteção. }\end{array}$ & $\begin{array}{l}\text { Isolar a área na base da escada oferecendo mais } \\
\text { proteção para a família. }\end{array}$ \\
\hline
\end{tabular}

\subsection{Primeiros Detalhes Arquitetônicos}

Com base no resultado das recomendações ergonômicas foi desenvolvida uma proposta para readequação do restaurante familiar. O primeiro ponto modificado foi o leiaute (Figura 20), proporcionando ao restaurante maior área de circulação. Uma das principais modificações do leiaute do ambiente, foi a mudança do local do caixa que é apresentado como o primeiro local a ser utilizado pelo cliente, otimizando o fluxo dentro do ambiente.

Figura 20: Leiaute de proposta. Fonte: Desenvolvido pelos autores (2019).

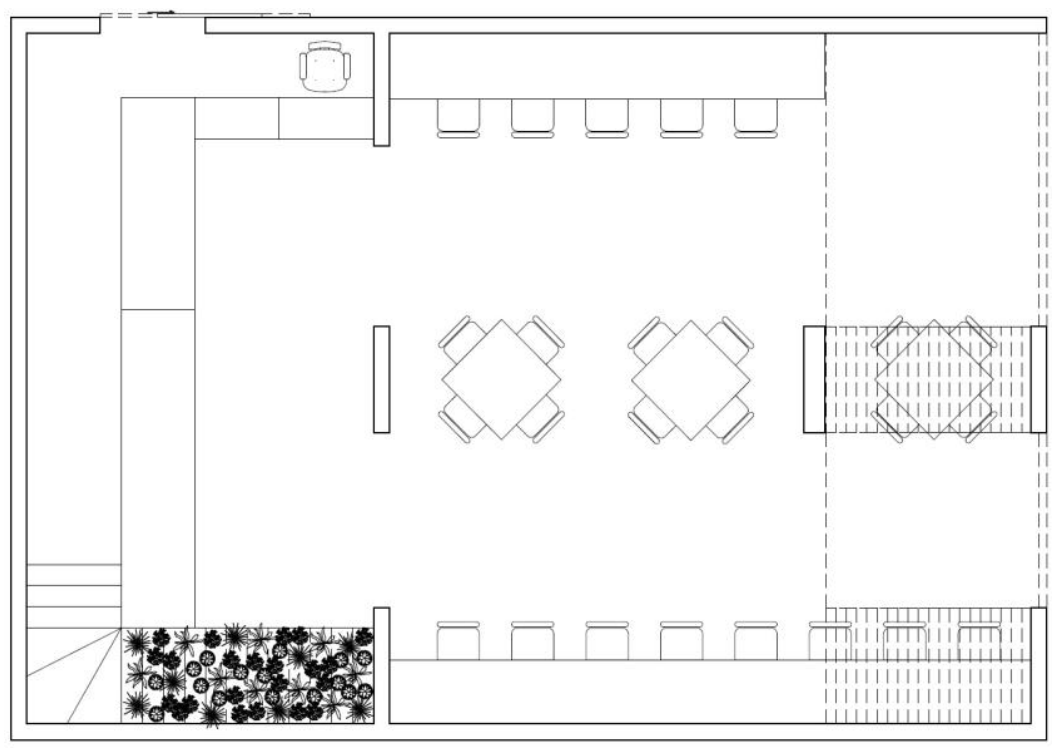

Outra mudança no leiaute, foram as áreas de circulação exclusiva para funcionários, o acesso a essa área se dá pelo balcão, logo após o caixa, que se eleva liberando o espaço para a circulação. A planta da proposta foi submetida a uma análise de circulação utilizando os modelos antropométricos, simulando o uso do novo ambiente. 


\section{$17^{\circ}$ ERGODESIGN \& USIHC 2019}

PUC-Rio, 11 a 13 de dezembro

Rio de Janeiro, RJ, Brasil $17^{\circ}$ Ergodesign - Congresso Internacional de Ergonomia e Usabilidade de Interfaces Humano Tecnológica: Produto, Informações Ambientes Construídos e Transporte $17^{\circ}$ USIHC - Congresso Internacional de Ergonomia e Usabilidade de Interfaces Humano Computador

Figura 21: Circulação na planta proposta. Fonte: Desenvolvido pelos autores (2019).

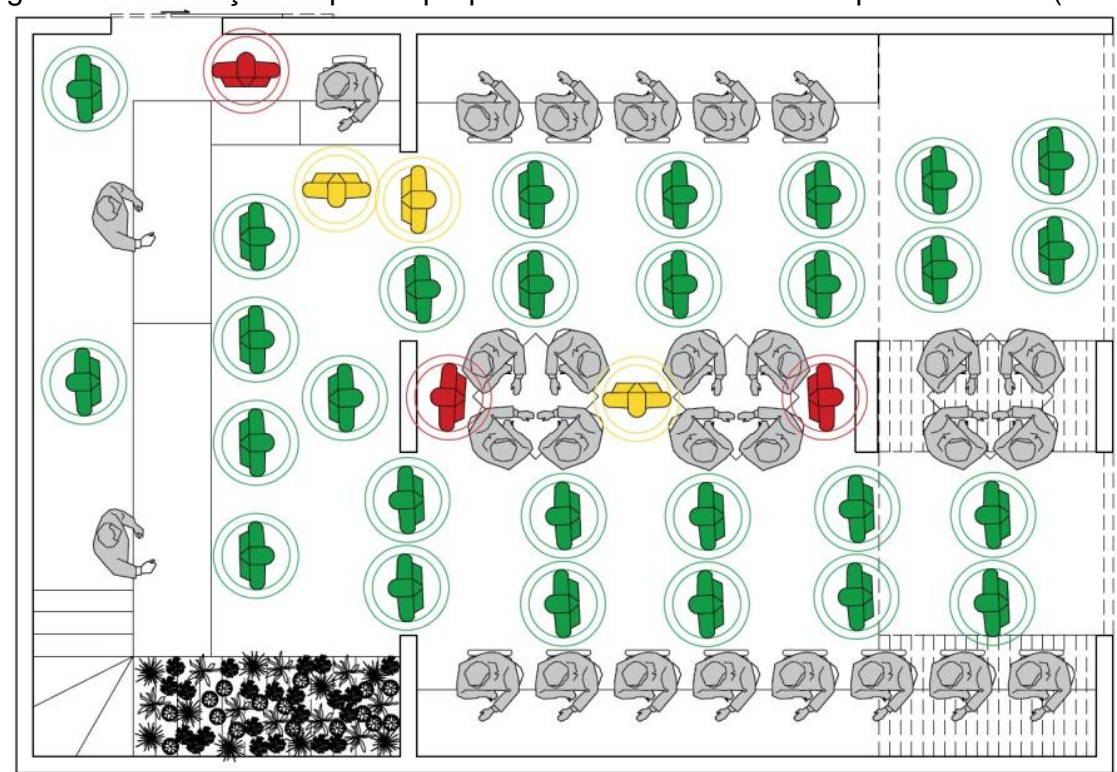

Com isso, foi possível notar o aumento de espaços considerados adequados para uma circulação livre de obstáculos. Houve redução significativa dos pontos inadequados, ficando somente na área do funcionário do caixa e em alguns setores próximo as mesas centrais.

Também foi verificada a circulação de acessibilidade da proposta (Figura 22).

Figura 22: Circulação acessível proposta. Fonte: Desenvolvido pelos autores (2019).

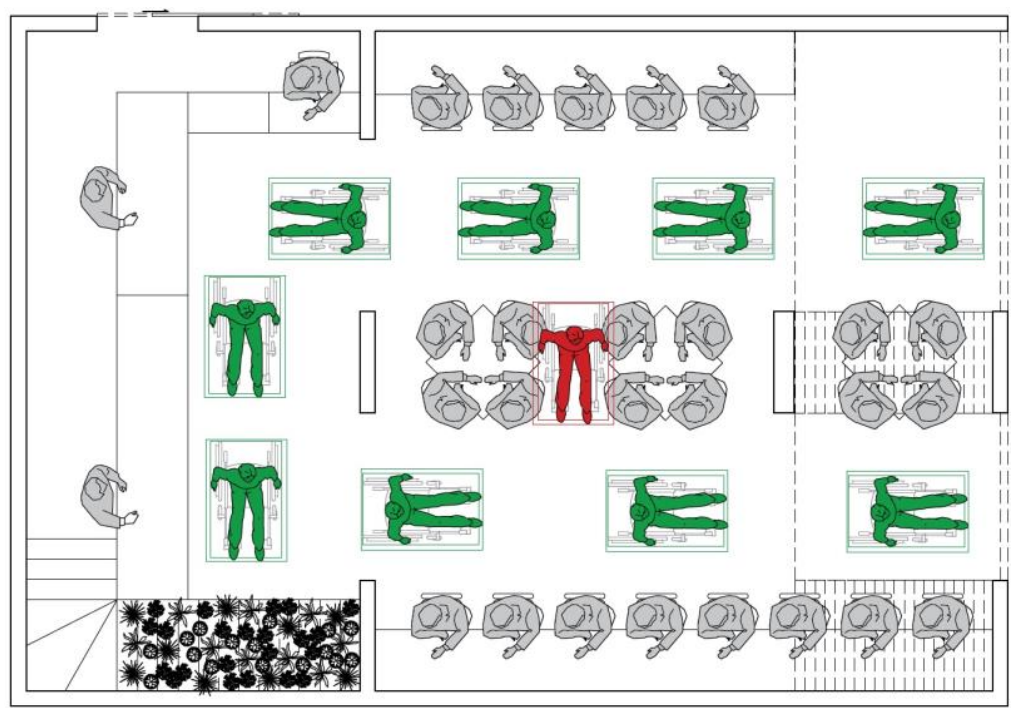

O cadeirante conseguiria percorrer todos os corredores principais e realizar todo o percurso do restaurante: entrada, serviço e saída. É notória a redução de áreas críticas, permanecendo apenas na área entre as mesas centrais. 


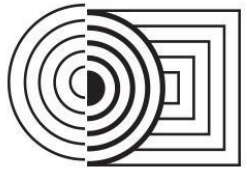

$17^{\circ}$ ERGODESIGN \& USIHC 2019

PUC-Rio, 11 a 13 de dezembro

Rio de Janeiro, RJ, Brasil $17^{\circ}$ Ergodesign - Congresso Internacional de Ergonomia e Usabilidade de Interfaces Humano Tecnológica: Produto, Informações Ambientes Construídos e Transporte $17^{\circ}$ USIHC - Congresso Internacional de Ergonomia e Usabilidade de Interfaces Humano Computador

\section{CONCLUSÃO}

Através deste estudo foi percebido que a área de refeições do restaurante familiar, oferece riscos ao usuários e aos funcionários e não está totalmente adequada para o princípio a qual é destinada. A estrutura impossibilita a realização de algumas tarefas simples, tanto para os funcionários quanto para os clientes. A área com $51,30 \mathrm{~m}^{2}$ não comporta devidamente o mobiliário e, por consequência, a demanda de pessoas do local, assim necessita passar pelas readequações apresentadas no quadro de proposições ergonômicas e na proposta, para oferecer aos usuários um ambiente mais confortável e ergonômico. Desta forma, acreditamos que investimentos da prefeitura municipal devam ser realizados no sentido de orientar a população acerca das necessidades distintas que configuram ambientes residenciais e ambientes comerciais.

A instalação de novos centros universitários deveria vir acompanhada de um estudo de viabilidade urbana, o qual incluísse a verificação do nível de desenvolvimento das edificações do entorno das instituições, desta forma seria verificada a presença de restaurantes, supermercados, drogarias e hospitais na malha urbana que envolve a área de instalação do centro. Caso a área não apresentasse tais tipos de edificação, surgiria a demanda previamente publicizada, no sentido de estimular uma construção concomitante à do Campus. Dentro deste contexto, a pesquisa nos evidencia que os investimentos em educação devem caminhar lado a lado dos investimentos urbanos de cada município. Um trabalho em parceria pode vir a oferecer uma maior qualidade no desempenho das atividades e estudantes e profissionais envolvidos nas instalações de novos Campus universitários. Neste ponto, a Ergonomia se revela como forte ferramenta de diagnóstico de demandas, entretanto, seria bem mais adequado que as correções e adaptações fossem feitas ainda em fase projetual, evitando expor o ser humano a constrangimentos desnecessários.

\section{REFERÊNCIAS BIBLIOGRÁFICAS}

ASSOCIAÇÃO BRASILEIRA DE NORMAS TÉCNICAS. ABNT NBR 10152:1987 - Níveis de Ruído para Conforto Acústico. ABNT, Rio de janeiro. 1987.

ASSOCIAÇÃO BRASILEIRA DE NORMAS TÉCNICAS. ABNT NBR 5413:1992 - lluminância de Interiores. ABNT, Rio de janeiro. 1992.

ASSOCIAÇÃO BRASILEIRA DE NORMAS TÉCNICAS. ABNT NBR 9050:2015 - Acessibilidade a edificações, mobiliário, espaços e equipamentos urbanos. ABNT, Rio de janeiro. 2015.

ATTAIANESE Erminia; DUCA, Gabriella. Human factors and ergonomic principles in building design for life and work activities: an applied methodology. Special Issue: Ergonomics in Design - Part II. Theoretical Issues in Ergonomics Science. Volume 13, Issue 2, 2012. pg 187202.

BARROS, Bruno. Avaliação Antropométrica de Espaços de Circulação Interna de Ambientes: um método proposto. In: CIPED 2009: Congresso Internacional de Pesquisa em Design, 2009, Bauru. Congresso Internacional de Pesquisa em Design (CIPED), 2009.

BARROS, Bruno; SEABRA FILHO, Sadi . MACHIA (método de avaliação da circulação horizontal interna de ambientes): diretrizes de aplicação. In: 13ํ Ergodesign-usihc - 13ำ Congresso Internacional de Ergonomia e Usabilidade De Interfaces Humano-Tecnologia: 
Produto, Informações, Ambiente Construído e Transporte, 2013, Juiz de Fora. Anais do $13^{\circ}$ Ergodesign, 2013.

Carvalho, F.M. Contribuições da Ergonomia para projetos de Unidades de Alimentação. In: Anais do 13 Encontro Latino Americano de Iniciação Científica e 9 Encontro Latino Americano de Pós-Graduação; 2009 Out 16-17; São José dos Campos, SP. São José dos Campos: Universidade do Vale do Paraíba; 2009.

COLARES L.G., FREITAS C.M. Processo de trabalho e saúde de trabalhadores de uma unidade de alimentação e nutrição: entre a prescrição e o real do trabalho. Cad Saúde Pública. 2007;23(12):3011-20.

FERREIRA, M. T. H. A. Construir no Construído: Nó de Alcântara, Novos Pólos de Urbanidade Multifuncionais e Sustentáveis. Dissertação de mestrado. Mestrado em Arquitetura. Universidade Técnica de Lisboa - Faculdade de Arquitetura. Lisboa, 2012.

GORGULHO, B.M.; LIPI, M.; MARCHIONI, D.M.L. Qualidade nutricional das refeições servidas em uma unidade de alimentação e nutrição de uma indústria da região metropolitana de São

Paulo. Rev. Nutr. v. 24, n. 3, p. 463-472, 2011.

IIDA, Itiro. Ergonomia: projeto e produção. 2. Ed. São Paulo: Edgard Blücher, 2005.

KROEMER, K. H. E; GRANDJEAN, E. Manual de ergonomia: adaptando o trabalho ao homem. 5. Ed. Porto Alegre: Bookman, 2005.

MATOS, C.H.; PROENÇA, R.P.C. Condições de trabalho e estado nutricional de operadores do setor de alimentação coletiva: um estudo de caso. Rev. Nutr. v.16, n.4, p.493-502, 2003.

MONTEIRO, M.A.; RAMOS, C.G.; RIBEIRO, R.C.; GARCIA, M.A. Condições de trabalho em restaurantes comerciais de uma instituição pública de ensino. Mundo Saúde. 2014;38(3):30613.

PANERO, Julius; ZELNIK, Martin. Dimensionamento humano para espaços interiores. 1.Ed. Barcelona: Gustavo Gili, 2013. 